The Mechanism of Nature

being a Simple Approach to Modern Views on the Structure of Matter and Radiation. By Prof. E. N. da C. Andrade. Revised and enlarged edition. Pp. xii $+188+8$ plates. (London: G. Bell and Sons, Ltd., 1936.) 6s. net.

THIs book is chiefly intended for the man who has not had the advantage of a scientific education but is anxious to know something of modern scientific developments. There are no mathematical formulæ to put the reader off. Sir James Jeans says somewhere that without considerable mathematical knowledge it would be quite impossible for anyone to understand those branches of science which deal with the fundamental nature of the universe, as, for example, the theory of relativity, the theory of quanta and wave mechanics. So the reader must not expect to be able to do this unless he be a wellequipped mathematician. Prof. Andrade, however, is so skilful in the use of words that his statements impart all there is to know on these subjects short of the employment of mathematics.

In this, the fifth edition, the whole book has been revised and alterations and additions have been introduced to bring it into harmony with recent work. The treatment of cosmic rays has been modified to accord with advances made since the last edition, and a brief account is given of the recent discovery and meaning of heavy hydrogen, the neutron and the positron, of artificial radioactivity and the striking development of artificial transmutation of matter. The explanation of the cause of isotopes-substances which have the same chemical properties but different atomic weights-is of much interest; 'heavy hydrogen' is the most remarkable of these. Another matter of interest is the question of how artificial atomic transmutation was brought about, to which Lord Rutherford has contributed so much. It has, however, so far never produced weighable quantities of any new atom, but established the possibility of transmutation. This, of course, completely revolutionizes the classic ideas of the nature of the atom. All these are treated with admirable clearness by the author, who is a master of exposition where complicated matters are concerned.

H. L. C.

\section{Aftermath :}

a Supplement to the Golden Bough. By Sir James George Frazer. Pp. xx +494 . (London: Macmillan and Co., Ltd., 1936.) 2ls. net.

IT might seem that the twelve volumes of "The Golden Bough" had already covered the ground more than adequately, and stood in no need of a supplement, Here, however, the author has gathered together data, not numerous, which had escaped his attention previously, and the more important items of evidence bearing upon his arguments, which have accrued in field work since the publication of the last edition of the major work. Hence this new volume is a corpus of additional facts, corresponding in its division into chapters with the arrangement of topics in "The Golden Bough", but making no addition to theory, except by way of corroboration.
Much of the material will already be familiar to anthropologists, who have not failed to note on numerous occasions how investigations in these fields of inquiry have served to confirm interpretations first tentatively suggested in "The Golden Bough". Prof. Seligman's Frazer Lecture dealing with the magical ritual of kingship, of which his own investigations among the peoples of the Upper Nile formed the starting-point, affords perhaps the most striking instance of the prescience shown by Sir James, not once alone, but on many occasions.

Notwithstanding advancing years, the hand of Sir James has not lost its cunning. His latest work in no way falls behind its many predecessors in style and charm of diction.

\section{Marconi :}

the Man and his Wireless. By Orrin E. Dunlap, Jr. Pp. xxii $+360+16$ plates. (New York: The Macmillan Co., 1937.) 16s. net.

THE author gives a good and temperate account of the life-work of one of the world's greatest inventors. One of the early pioneers of radio attributed Marconi's success chiefly to his instinctive intuition as to what was wanted and the best way of getting the solution. It must not be forgotten that he had a company with plenty of capital behind him and that its success or failure depended upon the rapid development of radio in the early days. With this money behind him he had the courage to launch out on great experiments. The fact also that the organization was called the Marconi Company added greatly to his prestige and always kept his name prominently before the world. When 'Cables obtained control of Wireless' in England, and the Marconi Company became practically a manufacturing organization, the most interesting period of its life had passed.

The author describes both the 'man' and the 'inventor', and links them together into one personality. Marconi crossed the Atlantic eighty-nine times on voyages of scientific research and good will. This view of him from an American angle throws much light on his career. We hope that it will not become customary in the United States to refer to Oliver Heaviside as Sir Oliver Heaviside.

\section{Hardness of Metals}

By Dr. F. C. Lea. Pp. vii + 141. (London: Charles Griffin and Co., Ltd., 1936.) 12s. 6d. net.

The hardness of metals, as Dr. Hugh O'Neill once said, like the storminess of seas, is easily appreciated but not readily measured. Prof. Lea has attempted to describe the various methods of measuring hardness, to establish, from the results of a long series of tests, the relationships between hardness measured by each of these methods, and thence, by means of curves and a chart, to make it possible within certain limits of accuracy to obtain corresponding hardness numbers as determined by the various methods. The book is not so much a discussion of 'the hardness of metals', therefore, as a collection of hardness data obtained on a series of materials comprising chiefly heat-treated steels. 